\title{
A Study on College Students' Network Assistance and Universities' Strategies: Case Studies
}

\author{
Chen Chih-Chung ${ }^{1} \&$ Li Jing ${ }^{1}$ \\ ${ }^{1}$ School of Journalism and Communication, Jinan University, Guangzhou, China \\ Correspondence: Chen Chih-Chung, School of Journalism and Communication, Jinan University, Guangzhou \\ 510632, China. E-mail: tchenzz03@jnu.edu.cn
}

Received: January 16, 2014 Accepted: June 24, 2014 Online Published: July 24, 2014

doi:10.5539/ass.v10n16p139 URL: http://dx.doi.org/10.5539/ass.v10n16p139

\begin{abstract}
It is the development in media that has promoted the formation of network assistance. Effective transmission of online assistance results from the construction of persuasive topics, the echoes of traditional and network public opinion fields and the mutual guidance of leading groups. As a result, commitment is encouraged through the process of network assistance, providing a useful trial to expand the channel for social assistance, which reveals the specific strategies adopted by universities.
\end{abstract}

Keywords: college students, network assistance, network mobilization

Rooted from Internet, network assistance serves as a new channel for social assistance. According to relevant data in The $30^{\text {th }}$ Statistical Report on China's Internet Development, by the end of July in 2012, the number of netizens had reached 538 million among which young people aged between 20 and 39 accounted for $55.7 \%$ with the total of nearly 300 million. It is obvious that college students are the dominant force on the net. Compared with traditional social assistance, network assistance appeals to young people more. Actually, such cases have aroused great sensations nowadays. However, relevant researches are insufficient or sketchy (Zhang, 2006). Therefore, this article is intended to explore into three typical cases about college students' seek for assistance via the microblog and try to find the characteristics of effective network assistance transmission and specific strategies for universities to face students' simultaneous assistance acts. This will be of great value in offering reference to guiding college students' internet behavior and maintaining campus stability.

\section{Changes in Media and the Formation of College Students' Network Assistance}

With medium being the carrier of information, constant changes in medium technology is closely related to historical and social progress. With the arrival of the Web 2.0 era represented by the microblog, we have entered the we-media age. Accordingly, we-media, with its top-to-bottom structure, free, open and casual style and an easy access for sharing, has completely changed current interpersonal relationships, power structure and the rules of transmission games (Lu, 2007).

Internet, rather than a neutral carrier or tool, comprises society, politics, economics, culture and human nature. During its operation and utilization, internet technology brings with it people's purposes, interests, standards, desires and value from different social ranks. As a result, netizens' appeals can be largely satisfied, especially in network assistance. Network assistance in such virtual reality is a process of desire expression, interest appeals and love conveying among individuals, groups and even institutions on a new platform and their comprehensive interaction with each other.

Network assistance refers to the act taken by internet users to publicize assistance information and arouse others' resonance on the internet in order to fulfill the purpose of assistance. It is the incomplete Chinese social security system and low coverage of official assistance and narrow assistance channels that lead to insufficient social assistance. As a newly-born assistance platform, the universality and interactivity of Internet make it possible for assistance appeals to be responded and therefore to achieve the purpose of assisting others. Compared with official assistance, network assistance is easier to be accepted by recipients.

However, due to the delegation of the right of speech, the shortage of administrators and different backgrounds of users, the microblog has become a field stricken by rumors. What's worse, some sentimental remarks tend to arouse netizens' interaction on some hot issues, hence forming a field of public opinion and leading to waves of 
groups. Accordingly, some scholars have pointed out that network opinion may not be in proper proportion with social opinion and such interaction in the network field tends to arouse extreme views or even network group events (He, 2010). The vast amount of assistance information has plunged some netizens into numbness. Therefore, it is noteworthy how to conduct network assistance in an effective way.

This article chooses three cases (Li Jing, Yantai Yu \& Xu Tao's cases of rescuing their parents) (Table 1) to analyze the transmission effect of such network assistance conducted by college students and to come up with relevant strategies in combination with universities' reality. The reasons to include the three cases are as follows: first, these are all college students' spontaneous assistance via a network medium; second, they are successful in view of the process in that they have aroused assistance in the virtual and real world and gain the donation of over 100,000 yuan; third, the assistance process witnesses the active participation of the subject's universities, the opinion leaders, the traditional media and the network media. The study on the above three cases, instead of any random one, reveals the popularity of network assistance, hence helping the exploration into the transmission pattern for college students' network assistance and expanding assistance channels.

Table 1. Cases of college students' network assistance

\begin{tabular}{|c|c|c|c|c|c|c|c|}
\hline & & Cause & $\begin{array}{l}\text { transmission } \\
\text { channel }\end{array}$ & subject & purpose & & result \\
\hline $\begin{array}{l}\text { Yang } \\
\text { assisting } \\
\text { mother }\end{array}$ & $\begin{array}{r}\text { Taiyu } \\
\text { his }\end{array}$ & $\begin{array}{l}\text { His mother needs } \\
\text { money for her } \\
\text { acute disease. }\end{array}$ & $\begin{array}{l}\text { Network (mainly } \\
\text { microblog) }\end{array}$ & $\begin{array}{l}\text { College } \\
\text { students }\end{array}$ & $\begin{array}{l}\text { Assisting } \\
\text { family } \\
\text { member }\end{array}$ & $\mathrm{a}$ & $\begin{array}{l}\text { He got nearly } 160,000 \text { yuan } \\
\text { for his mother's treatment } \\
\text { and his mother got cured. }\end{array}$ \\
\hline $\begin{array}{l}\mathrm{Li} \\
\text { assisting } \\
\text { father }\end{array}$ & $\begin{array}{r}\text { Jing } \\
\text { her }\end{array}$ & $\begin{array}{l}\text { His father needs } \\
\text { money for his } \\
\text { cancer. }\end{array}$ & $\begin{array}{l}\text { Network (mainly } \\
\text { microblog) }\end{array}$ & $\begin{array}{l}\text { College } \\
\text { students }\end{array}$ & $\begin{array}{l}\text { Assisting } \\
\text { family } \\
\text { member }\end{array}$ & $\mathrm{a}$ & $\begin{array}{l}\text { She got nearly } 170,000 \text { yuan } \\
\text { for his father but finally his } \\
\text { father died. }\end{array}$ \\
\hline $\begin{array}{l}\mathrm{Xu} \\
\text { assisting } \\
\text { father }\end{array}$ & $\begin{array}{r}\text { Tao } \\
\text { his }\end{array}$ & $\begin{array}{l}\text { His father needs } \\
\text { money for his } \\
\text { cancer. }\end{array}$ & $\begin{array}{l}\text { Network (mainly } \\
\text { microblog, BBS) }\end{array}$ & $\begin{array}{l}\text { College } \\
\text { students }\end{array}$ & $\begin{array}{l}\text { Assisting } \\
\text { family } \\
\text { member }\end{array}$ & $\mathrm{a}$ & $\begin{array}{l}\text { He got nearly } 300,000 \text { yuan } \\
\text { for his father's treatment and } \\
\text { he got cured finally. }\end{array}$ \\
\hline
\end{tabular}

\section{The Transmission Characteristics of College Students' Network Assistance}

Despite their differences, the above three cases have the characteristics of the transmission process in common. It is such an effective transmission that makes assistance successful.

\subsection{The Construction of Persuasive Topics: The Interaction of Information Sources and College Students}

The truth of information sources serves as an important factor for the success in persuading recipients. According to Hovland, when an individual publicizes a piece of information for assistance, it may cause recipients' resistance and lead to a sleeper effect because the low credibility of the information sources me a discount cue (Franzoi, 2010). Despite of the significance of information credibility for the short-term effect, the persuasiveness of the information itself is the truly decisive one for the long run (Guo, 1999). These cases, based on sadness, helplessness and aspiration, create a context for the weak and arouse people's recognition of assistance. Once the recipients' empathy is aroused, they tend to be placed in others' situations to experience the rescuer's situation and emotion and therefore conduct altruist acts to help others for nothing.

When college students have group transmission based on public welfare charity topics, their interaction and communication help to form group awareness and promote assistance activities. In a group, public opinion is the most important context stress dominating whether one follows the trend. The opinion mentioned or emphasized by the majority is liable to be regarded as the mainstream one or a promising one. When one feels that he falls into the majority, he will be confident to state his opinion in public while the other may keep silent when he is a member of the minority. One's silence may enhance the other's strength, which, in return, forces more people with different opinions into silence, hence forming a spiral effect of silence proposed by Neumann (Guo, 1999). In the above cases, about 1500 students from 12 universities participated in Yang Taiyu's assistance of his mother; in Xu Tao's assistance of his father, BUCTER as one of the gathering field of young people conducted assistance acts first of all; Li Jing's assistance with her father started from the microblog. College students, the most sensitive and fashionable group in the current society, take the microblog as an outlet for their emotions, which carries the users' appeals for releasing emotions, recording life and displaying opinions (2011). Via the microblog, college students form their universal opinion through their interaction, hence creating a virtual environment for assistance. Some may doubt the truth of the event during the course, but a spiral effect may 
occur to the minority once the majority turn to the supportive trend. Although high-credibility information is more persuasive than the lower one when the information is revealed, its credibility will be weakened with time. In this case, the propelling force of the group is important in which the joint force enhances the persuasiveness of the assistance information and exerts a critical effect on the assistance process.

\subsection{The Cooperation of Two Fields of Public Opinion: Mutual Promotion of the Traditional and the Network Fields of Public Opinion}

With the development of medium technology, the changes in context and public opinion make it possible for the traditional field of public opinion dominated by traditional media and the network field of public opinion characterized by we-media to coexist at the same time. In the case of network assistance, the traditional field of public opinion exerts a stronger force than the network one. Regardless of its better timeliness, the persuasiveness and authority of the microblog is doubted. Comparatively, the traditional media, with its strict standards on authenticity and more profound reflection, is more creditable. Based on its values, the traditional media make the assistance information the focus of social attention in different ways, exerting direct and profound influences on the formation of social hot issues and the tendency of public opinion ( $\mathrm{Qu}, 2011)$.

It is noteworthy that the traditional media have also developed electronic media to achieve the co-development of paper and network media, to create a virtual ecological environment based on assistance on the internet and in the real life, to influence the awareness and behavior of recipients. With the same attitude and the same opinion, both fields jointly push an issue to the summit of public opinion. In some cases, both paper media such as China Youth Daily, Nanfang Daily, Beijing Youth Daily, Dahe Daily, and network media including Ifeng.com, Netease, Ynet, Hebei.com traced the development of the event jointly, forming universal opinions in both fields. It is those positive reports that exert the social function of mass media on public opinion and forces the negative opinion silent, hence enhancing positive opinion and guiding public opinion to the right direction (Chen, 1999). Meanwhile, the massive recipient group, high creditability and organization capacity of the traditional media are taken advantage of to realize the combination of the virtual world and the real world and therefore to accomplish the goal of mobilizing network resources and to realize the common advances of network and traditional fields of public opinion (Chen, 1999).

\subsection{The Guidance of the Opinion Leading Groups: Joint Guidance of Public and University Leading Groups}

In modern media, what we mention as the opinion leader refers to not only individuals but the microblogs held by universities, communities and teachers authenticated with their real names. They usually break information barriers and attach their attention to some hot issues and rapidly spread the information with some available tools such as attention, reply, comment, thus arousing the information flow among different netizen groups. During this course, the opinion leader influences the netizens' viewpoints and directs their interest to some hot issues and therefore expands the battlefield.

The opinion leader takes the lead in the network assistance process by not only guiding the trend of helping others in the way of interpersonal relationship transmission but influencing the direction of public opinion in a subtle way. The above cases only got a handful of replies at the initial stage along with some doubtful voices. Not until the authenticity of the information got verified and the opinion leader replied did the real assistance process begin. In Xu Tao's case, his appeal got verified by the official microblog and the BBS of his school, Beijing University of Chemical Technology, and was replied by Murong Xuecun, a writer with over 2,500,000 fans, as well as Qin Lan, an actress with over 1,700,000 fans. As a result, more people replied to and remarked on Xu Tao's assistance information, creating the climax of the whole campaign, followed by another peak aroused by Xu Xiaoping who is the founder of Zhen Fund and a joint founder of New Oriental School. The Same story happened in the other two cases as well, in which Li Jing and Yang Taiyu's appeals for help got verified by their schools' official microblog first and were replied by some opinion leaders with a large group of fans. As a result, the peak of the whole donation campaign was achieved.

\section{Strategies of Universities in Student Work}

Network assistance has a double-side nature: while releasing positive energy, it also poses potential threats to the stability of universities. Therefore, universities should meticulously examine the situation, understand the dissemination rule and correctly guide the development of the campaign.

\subsection{Role Switch of Universities in Network Assistance from the Controller to the Participant}

In mobilizing public opinion in assistance, media or individuals can either amplify positive emotions, or strengthen certain negative ones. Negative emotion based public opinion is the behavior to expose hostility and behavior of panic madness, with the aim of disseminating ideas or venting their emotions (sometimes even the 
groups involved are not aware). Young college students do not reason on group behavior. "The concept is either accepted entirely or rejected completely by college students; those hints with influences on them will have a complete dominance over their understanding capacity and plunge them into a prompt action. With their group influenced in a proper way, they tend to sacrifice everything for their goal (Chen, 1999)." Therefore, universities tend to adopt measures to suppress public opinion. However, in the "transparent" network society, this conservative approach not only fails to suppress public opinion, it will also give rise to resistance to the behavior of the university by network users and jeopardise the assistance.

In the mentioned cases, the official organizations of Beijing University of Chemical Technology, Jinan University and Shangqiu Normal University have set the development of the events through opinion leaders of college students and official microblogs, taking full advantage of the features of agenda setting. Take Jinan University for example, at the beginning of the mobilization process, more than 30 official microblogs, such as Jinan University, Jinan University Home on Renren, Student Union of Jinan University (Zhuhai Campus), have forwarded and commented on the event, which have eliminated the doubt of netizens and appealed for donation. It is observed that the role switch of universities from the controller to the participant could prompt positive development of network mobilization.

\subsection{The Transition of the Scope of Mobilization from Universities' Resources to Social Resources}

The injection of resources or external forces is the most important factor in the formation of network mobilization. Among them, the development of news media equips the mobilization campaign unprecedented support means, which averts mobilization difficulties due to the lack of close contact. In this context, network assistance topics offered by individuals arouse the participation of social network, online media; opinion leaders, traditional paper media and universities, and promote mobilization into practical action. In this process, the scope of mobilization extends from the university to the whole society, broadening the assistance channel and making up for the lack of official assistance. The expansion of resource mobilization could receive mobilization support in a broader scope, and maximize the benefits for those who receive assistance.

\subsection{The Significance of Agenda Setting: The Opinion Leader Leading the Trend of Public Opinion}

Although it is difficult to set the agenda in the new media situation, it is indisputable that the direction of public opinion is influenced by the opinion leader. Generally, the media put some questions that the public have not noticed on the agenda, draw public attention and develop discussions, so that public opinion consistent with media direction could be formed. Before the involvement of the media in network mobilization, the power of opinion leaders, to some extent, is equivalent to the media. Opinion leaders could strengthen the agenda-setting of assistance issues, as agenda-setting has great influences on the public and improve the public's interest on the issues at the early stage of defining a certain social issue. Public agenda tends to be much affected by latest media information received, while the mobility of media information defines the features of the choice and memorization of such information by the public: temporality and constant expectation for future information. Opinion leaders can guide the public opinion in the early stage of mobilization so that the mobilization could be conducive to the fulfillment of the purpose of the assistance action.

Through the above analysis and discussion, it is observed that universities should give full play to the characteristics of opinion leaders and agenda-setting, switch roles and expand the channel of aid resources so as to expand the public opinion field to one covering the whole society and therefore mobilize social resources to be collected for assistance. Meanwhile, universities should release timely screening of aid information, cooperate with traditional media and online media in the positive dissemination, and promote the networking and socialization of network assistance.

\section{References}

A Report on the Microblog: When College Students Encounter the Microblog. (2011). Retrieved from http://edu.qq.com/a/20110510/000269.htm

Chen, L. D. (1999). Studies of Public Opinion: Research on the Direction of Public Opinion. Beijing: China Broadcast and Television Press.

Franzoi, S. (n. d.). Social Psychology. Shanghai: Shanghai People's Press.

Guo, Q. G. (1999). The Course of Communication (p. 200). Beijing: China People's Press.

He, G. P. (2010). Mobilization Pattern and Opinion Guidance of Network Group Events. Exploration, (6).

Le Bon, G. (2005). People's Psychology. Beijing: Central Compilation and Translation Press.

Lu, S. M. (2007). Communication. Beijing: China People's Press. 
Qu, X. (2011). The Countermeasures of Paper Media against the Micro-Era. Journalist Cradle, (7).

Yang, J. N. (n. d.). The Origin and Development of the Theory of Resource Mobilization. Retrieved from http://blog.sina.com.cn/s/blog_4c721e9b01000854.html

Zhang, Y. D., \& Zhou, S. Q. (2007). Mobilization of Resources and Network Civil Assistance. Society, (3).

\section{Copyrights}

Copyright for this article is retained by the author(s), with first publication rights granted to the journal.

This is an open-access article distributed under the terms and conditions of the Creative Commons Attribution license (http://creativecommons.org/licenses/by/3.0/). 